\title{
Psicologia Escolar e Relação Família-Escola: Um Levantamento da Literatura
}

\author{
Jéssica Andrade de Albuquerque \\ Fabiola de Sousa Braz, Aquino ${ }^{1}$ \\ ${ }^{1}$ Universidade Federal da Paraíba, João Pessoa, PB
}

\begin{abstract}
Resumo
A relação família-escola tem sido marcada por tensões e conflitos que repercutem no aprendizado de estudantes e na dinâmica institucional. Com o objetivo de ampliar a compreensão acerca desse tema, foi realizado um levantamento da literatura sobre as intervenções na área da psicologia escolar direcionadas à relação família-escola em bases de dados científicas. Os resultados do levantamento revelaram escassez de estudos que abordam intervenções de psicólogos escolares na relação família-escola. Tal fato permite sugerir a necessidade de desenvolver propostas de intervenção voltadas a essa questão, envolvendo os diferentes segmentos da escola.

Palavras-chave: psicologia escolar, escola, família, intervenção
\end{abstract}

\begin{abstract}
School psychology and family-school relationship: a literature review

The family-school relationship has been marked by tensions and conflicts that reverberate on student learning and institutional dynamics. Aiming to expand the understanding of this theme, it was performed a literature review about the interventions in the area of School Psychology aimed at the family-school relationship in scientific databases. The results revealed a shortage of studies that mention interventions of the school psychologist in the family-school relationship. This fact indicates the need to develop intervention proposals focused on this issue, involving the different segments of the school.

Keywords: school psychology; school; family; intervention.
\end{abstract}

\section{Resumen}

Psicología escolar y relación familia-escuela: un levantamiento de literatura.

La relación familia-escuela ha sido marcada por tensiones y conflictos que repercuten en el aprendizaje de los estudiantes y la dinámica institucional. Con objetivo de ampliar la comprensión sobre este tema, se realizó un estudio de literatura sobre las intervenciones en el campo de la psicología escolar dirigido a la relación familia-escuela en bases de datos científicas. Los resultados revelaron pocos estudios relacionados con las intervenciones de los psicólogos escolares en relación familia-escuela. Tal hecho permite sugerir la necesidad de desarrollar propuestas de intervención dirigidas a este tema, con la participación de los diferentes segmentos de la escuela.

Palabras-clave: Psicología escolar; escuela; familia; intervención.

O presente artigo é parte de um estudo mais amplo de dissertação de mestrado, que tem por objetivo investigar as concepções de familiares e agentes escolares sobre a relação família-escola, discutindo, em especial, a atuação do psicólogo escolar nesse tipo de relação.

A relevância e a atualidade dessa discussão são demonstradas em pesquisas realizadas com profissionais de escolas públicas, tais como gestores, professores e psicólogos (Cavalcante \& Aquino, 2013; Aquino, Lins, Cavalcante, \& Gomes 2015; Silva, Aquino, Albuquerque \& Rodrigues, 2015). As citadas pesquisadoras apontam, como uma das principais causas das queixas escolares direcionadas aos psicólogos, o tipo de participação da família no processo de escolarização dos filhos. De acordo com a maioria desses estudos, a família é considerada como ausente dos processos escolares dos filhos e apontada como um dos motivos pelos quais os estudantes não obtinham êxito nas atividades escolares.
A necessidade de abordar essa questão foi impulsionada também pela recorrência de queixas de profissionais de escolas públicas acerca das dificuldades de sua relação com as famílias das crianças inseridas nesses espaços. As queixas são frequentemente relatadas durante a realização de estágio supervisionado curricular em psicologia escolar (Silva, Aquino, Albuquerque \& Rodrigues, 2015; Braz-Aquino \& Albuquerque, 2016). Em estudo recente, Cavalcante (2015) identificou, como uma das principais dificuldades na atuação de psicólogos em contextos escolares, o trabalho referente à relação família-escola. $\mathrm{O}$ estudo constatou, a partir da concepção de agentes escolares, que a família é a principal responsável pelos problemas de comportamento e de envolvimento dos estudantes com a escola. A relevância do trabalho do psicólogo, na mediação da relação família-escola, é destacada pela National Association of School Psychologists (NASP) como parte das atribuições do psicólogo escolar. 
Pesquisas sobre esse tema vêm demonstrando que o campo relacional entre família e escola é marcado por conflitos e tensões (Bhering \& Siraj-Blatchford, 1999; Polonia \& Dessen, 2005; Reali \& Tancredi, 2005; Oliveira \& Marinho-Araújo, 2010; Marcondes \& Sigolo, 2012). De acordo com Oliveira (2002), a relação família-escola ocorre, muitas vezes, de maneira unilateral. É caracterizada pelo poder de orientação da escola sobre as famílias, culpabilização das famílias pelos entraves na educação dos filhos e ainda em razão da ausência de responsabilização compartilhada.

Diante dessas constatações, o presente trabalho teve como objetivo fazer um levantamento da literatura sobre as intervenções na área da psicologia escolar direcionadas ao contexto da relação família-escola. Buscou, especificamente, explorar intervenções de psicólogos escolares, no âmbito da relação família-escola, publicadas na literatura científica.

\section{Método}

Trata-se de um estudo fundamentado na revisão da literatura que foi desenvolvida a partir da leitura e identificação de artigos científicos, dissertações e teses na área da psicologia escolar, em interface com a relação família-escola. A pesquisa foi conduzida por meio dos descritores family, school e psychology educational, nas bases de dados Web of Science, Pubmed, SciELO, Lilacs, IndexPsi e Pepsic, bem como na Biblioteca Digital Brasileira de Teses e Dissertações (BDTD). A escolha dessas fontes de informações se justifica pela abrangência de estudos desenvolvidos no âmbito nacional e internacional. Convém esclarecer que os descritores foram inseridos nas respectivas bases, de acordo com o idioma oficial e a nomenclatura adotada por elas.

No processo de identificação das produções, foi realizada inicialmente uma busca simples nas referidas bases de dados. Dessa forma, foram inseridos os descritores e operadores boleanos. Posteriormente, foi feita uma busca sensibilizada, sendo inseridos, em cada busca, além dos descritores, seus sinônimos e categorias. É importante ressaltar que todos os periódicos pesquisados foram consultados em bases on-line.

Os critérios de inclusão para o levantamento consistiram em: (a) estudos teóricos, de pesquisa empírica ou de pesquisa-intervenção que abordavam a temática da relação família-escola no âmbito da psicologia escolar; (b) artigos indexados sem restrição de idioma ou delineamento metodológico; (c) artigos, dissertações ou teses publicados entre os anos de 2000 a 2016. Nos critérios de exclusão, foram observados dois fatores: (a) publicações anteriores ao ano de 2000; (b) artigos que não abordavam a temática em estudo.

A seleção das publicações foi organizada, inicialmente, a partir da leitura dos títulos e resumos das produções localizadas nas buscas. Com essa medida, foi possível excluir aquelas que claramente não atendiam aos objetivos do estudo. $\mathrm{Na}$ segunda etapa, idêntico procedimento foi adotado, porém a decisão pela exclusão foi baseada nas informações constantes na íntegra das produções. Por fim, foram selecionados os estudos que compuseram o presente levantamento. Para analisar as produções levantadas, elegeram-se as seguintes categorias: data das publicações e periódicos; autoria e vínculo institucional; delineamento da pesquisa; amostra e instrumentos utilizados; principais resultados dos estudos.

\section{Resultados e Discussão}

As primeiras buscas levaram aos seguintes resultados, no que diz respeito à quantidade de publicações: Web of Science: 132 artigos, SciELO: 75, Pubmed: 151, Lilacs:132, IndexPsi:42, Pepsic: 4. Na Biblioteca Digital Brasileira de Teses e Dissertações, foram localizadas 257 produções. Após a leitura dos títulos e resumos, restaram os seguintes números: Web of Science: 0, SciELO: 5, Pubmed: 0, Lilacs: 2, IndexPsi: 0, Pepsic: 1; Biblioteca Digital Brasileira de Teses e Dissertações: 10. Por fim, após a leitura das pesquisas na íntegra, a seleção das produções restringiu-se aos seguintes números finais: SciELO: 2, Lilacs: 1, Pepsic: 1 e Biblioteca Digital Brasileira de Teses e Dissertações: cinco, sendo quatro dissertações e uma tese de doutorado, totalizando nove produções a serem analisadas. O fluxograma da seleção das produções pode ser visualizado na Figura 1.

O número restrito de nove trabalhos a serem analisados justifica-se em razão de ser a temática pouco explorada no âmbito da psicologia escolar. Com base nessa constatação, Carvalho (2000) e Marques (2002) enfatizaram a urgência da geração de dados empíricos que possibilitem identificar os elementos que facilitam ou dificultam a relação entre família e escola. Acrescentam que, no Brasil, tem prevalecido mais o discurso sobre as necessidades de pesquisar do que a apresentação de dados relacionados à pesquisa sobre essa temática.

Embora o presente estudo tenha como objetivo a busca de produções sobre intervenções do psicólogo 


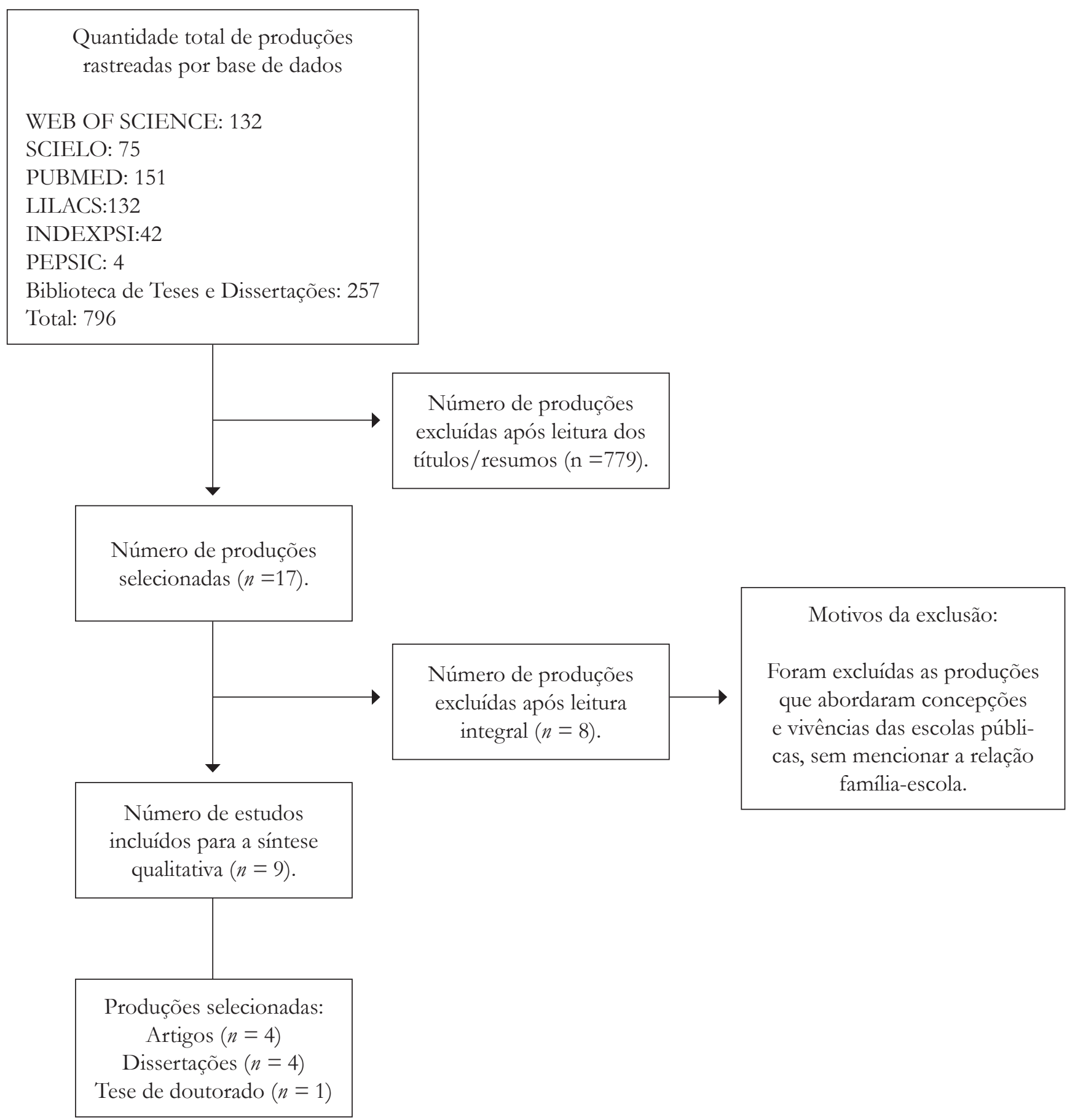

Figura 1. Fluxograma da seleção das produções.

escolar no contexto da relação família-escola, localizou-se apenas um artigo que aborda um tipo específico de intervenção realizada nesse contexto. Assim, dada a escassez de trabalhos sobre a temática, optou-se por incluir produções que investigaram a relação família-escola, a partir da perspectiva da psicologia escolar. Dessa forma, oito das nove pesquisas analisadas propuseram-se a investigar sistemicamente a relação entre escola e família. O Quadro 1, apresenta a síntese das produções incluídas na análise.

É importante esclarecer que os artigos, dissertações e teses, no processo de seleção das produções, envolviam investigações que tratavam de temas como: resiliência na educação, necessidades especiais, 


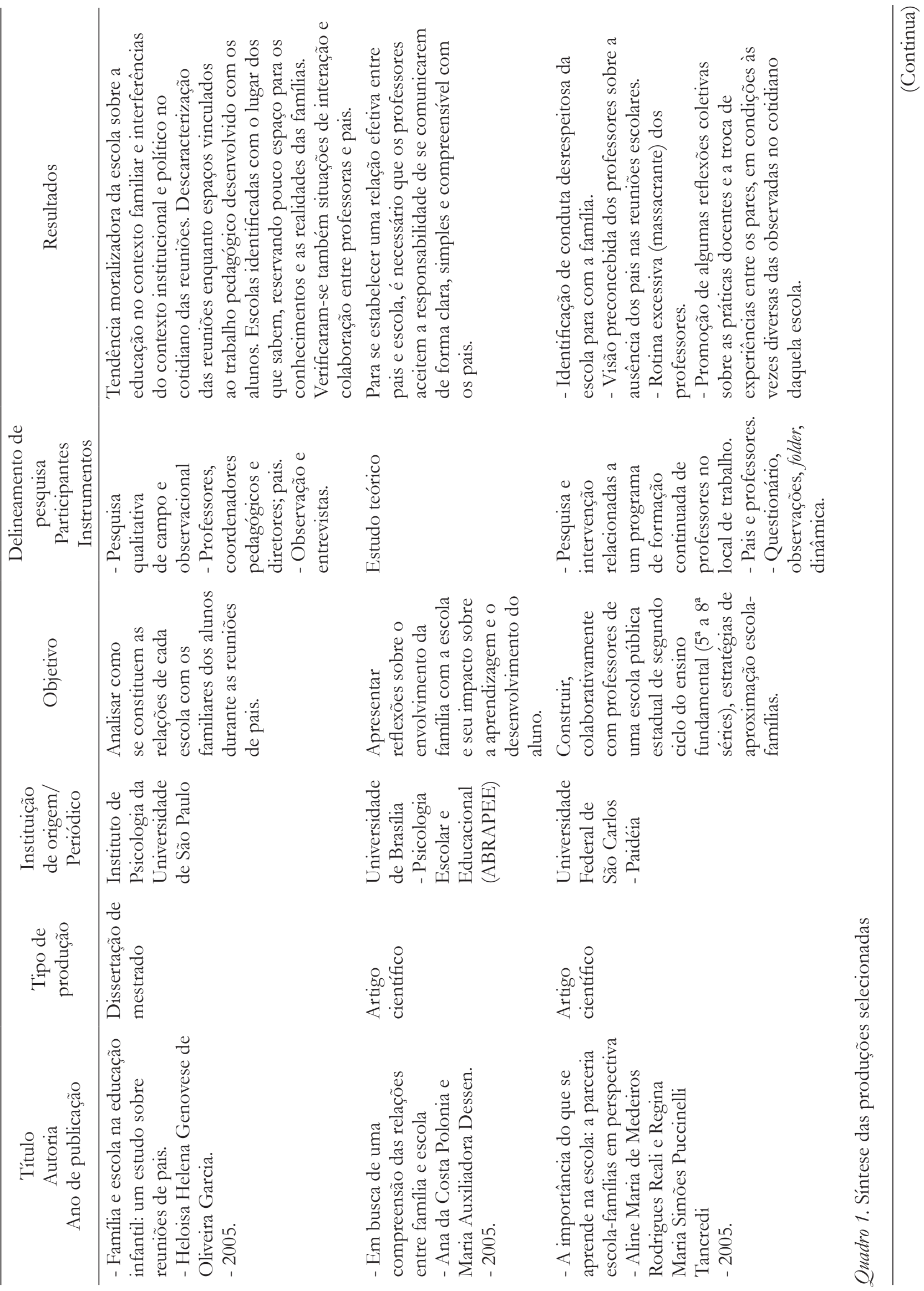




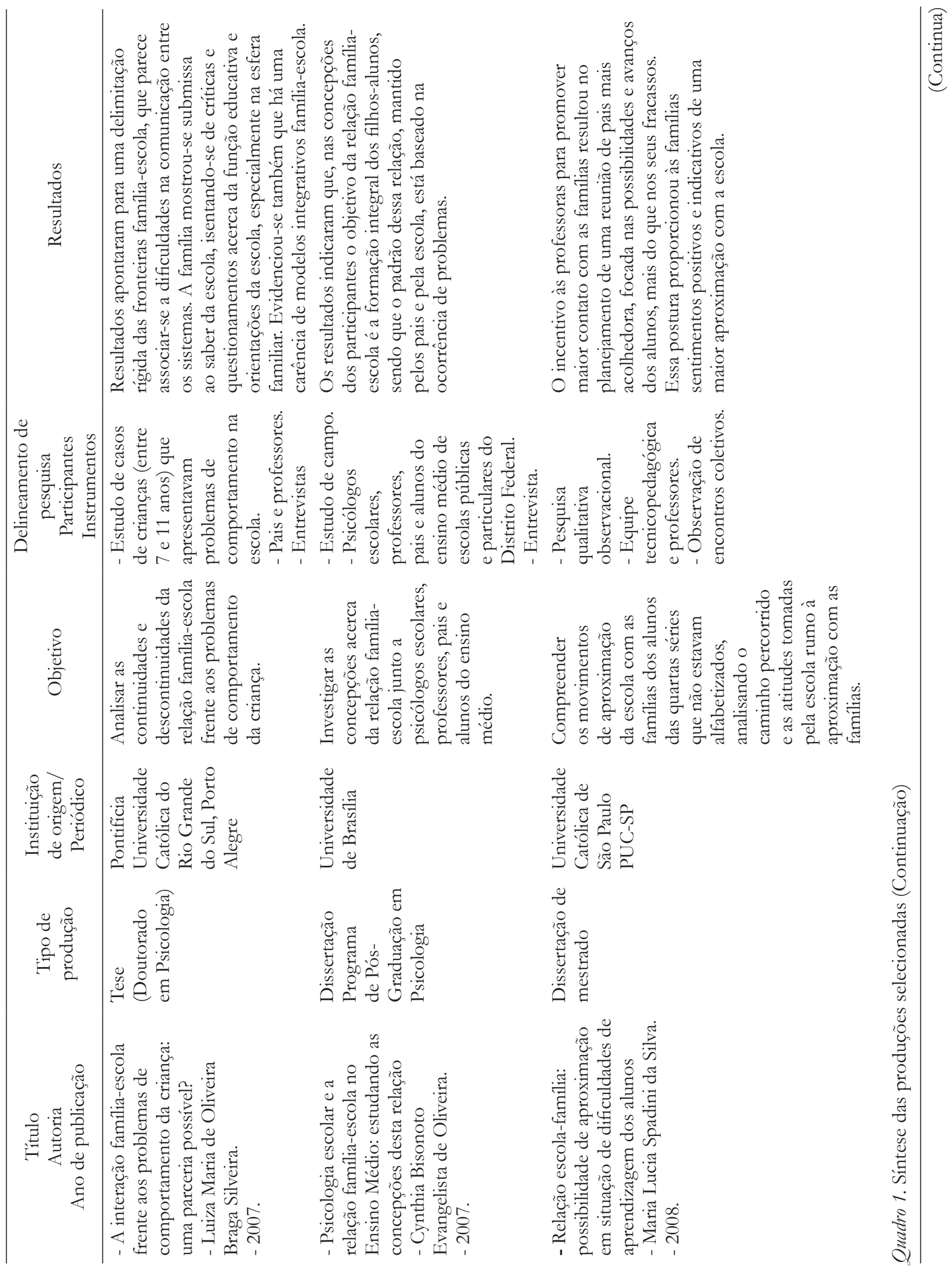




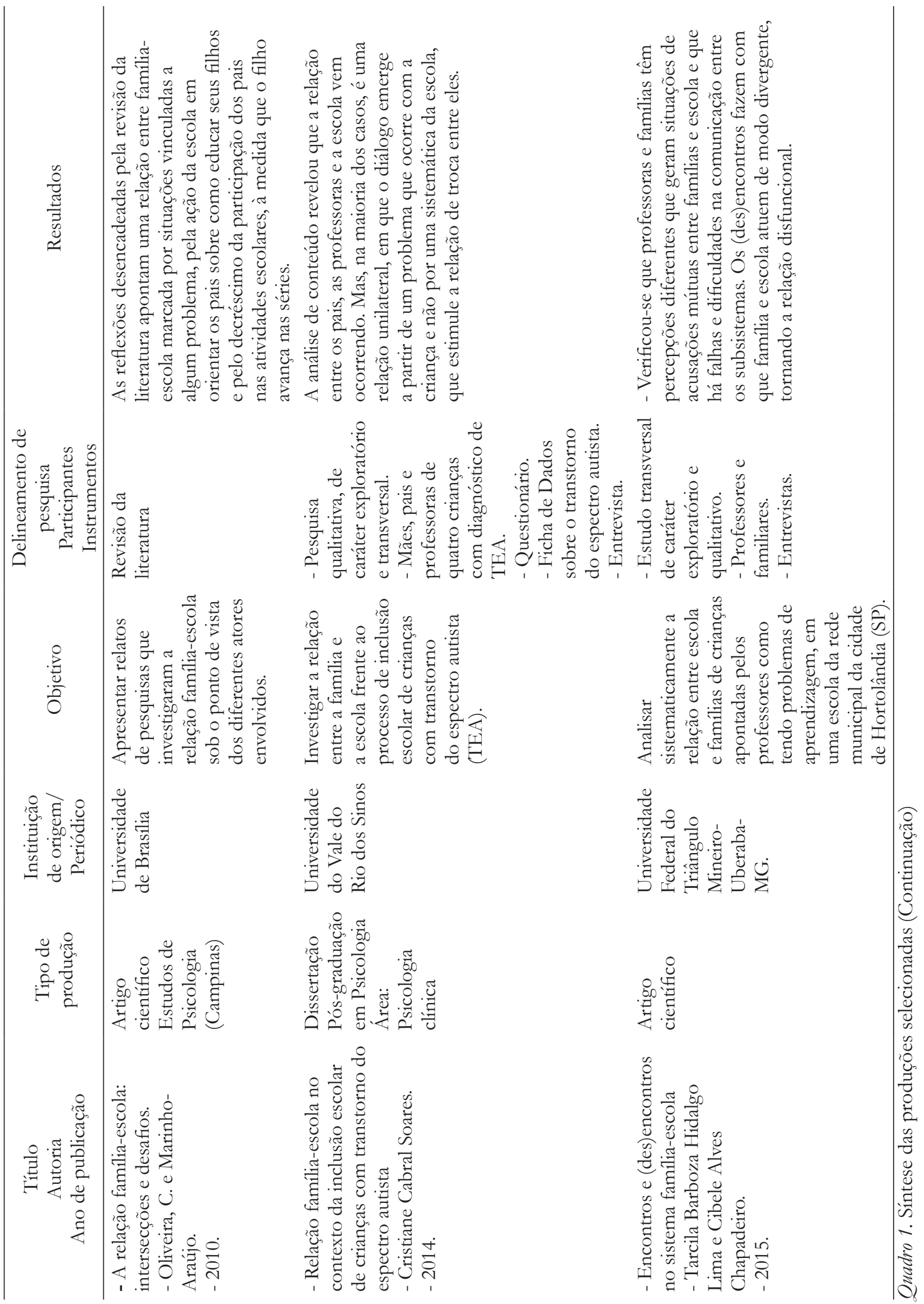


desempenho acadêmico, disparidades sociais na educação, bullying e discriminação nas escolas, transição cultural e rendimento acadêmico, envolvimento dos pais no aprendizado de crianças, ambiente familiar e dificuldades acadêmicas, prontidão escolar, divórcio e aprendizagem das crianças, frequência escolar, sucesso acadêmico, efeitos de estilos parentais na educação, comportamento escolar e planejamento educacional. Tais questões se afastam do tema objeto do presente trabalho, de modo que esses estudos foram excluídos da análise. Foram excluídas também as produções que mencionavam ora a família, ora a escola como propulsoras da escolarização de crianças, sem, contudo, focalizar a relação entre ambas.

\section{Data das Publicações e Periódicos}

A análise das pesquisas indicou que, apesar do recorte dos anos de 2000 a 2016, a relação família-escola foi tema de publicação, com maior frequência na área da psicologia escolar, no ano de 2005. A partir desse ano, a temática começou a ser publicada nos periódicos on-line, como pode ser observado no Gráfico 1. É possível observar que, desde sua inserção na comunidade científica, a temática vem sendo estudada até a atualidade. No entanto, o número de publicações é ainda reduzido, considerando a relevância da relação família-escola para o processo de escolarização das crianças.

Os artigos publicados nos periódicos abordaram, prioritariamente, a área da psicologia escolar. Do total de quatro artigos, quatro dissertações e uma tese de doutorado, dois artigos foram publicados em periódico específico na área da psicologia escolar (Psicologia Escolar e Educacional), enquanto os outros dois constaram em periódicos nacionais de psicologia (Estudos de Psicologia - Campinas e Paidéia).

As dissertações e teses foram acessadas pela Biblioteca Digital Brasileira de Teses e Dissertações (BDTD). Ela integra, em um único portal, os sistemas de informação de teses e dissertações existentes no Brasil. Disponibiliza aos usuários um catálogo nacional de teses e dissertações, com texto integral, possibilitando uma forma rápida de busca e acesso a esses documentos.

Convém salientar que a busca realizada privilegiou bases de dados internacionais, contudo não foram identificadas produções sobre a temática. Os estudos localizados em tais buscas estavam direcionados, principalmente, a questões como desempenho escolar, ambiente familiar e dificuldades acadêmicas, qualidades escolares, efeitos de estilos parentais na aprendizagem e comportamento escolar.

\section{Autoria e Vinculo Institucional}

No que se refere à autoria, das nove produções analisadas, quatro eram artigos de autoria coletiva. As outras cinco eram dissertações e tese, possuindo, portanto, autoria individual. Todos os autores dos trabalhos analisados eram do sexo feminino. Tal constatação ratifica a tradição da psicologia escolar educacional como um campo de conhecimento e atuação majoritariamente feminino (Oliveira, Cantalice, Joly, \& Santos, 2006). Em relação ao vínculo institucional, quatro autoras eram vinculadas a instituições localizadas na região Sul do Brasil, três a instituições da região Sudeste e duas a instituições da região Centro-Oeste do país.

Esses resultados corroboram os de outros estudos realizados por pesquisadores na área da psicologia escolar (Oliveira, Cantalice, Joly, \& Santos, 2006; Nunes, Alves, Ramalho, \& Aquino, 2014). Em todos esses estudos, verificou-se um maior número de produções nas regiões Sul e Sudeste do Brasil. O fato se justifica porque, nas duas regiões, existe maior número de cursos de psicologia, em nível de graduação e pós-graduação.

Além disso, as regiões citadas publicam uma maior quantidade de periódicos na área de psicologia. A partir do catálogo de revistas científicas disponível na Biblioteca Virtual de Saúde, observa-se que, no Brasil, existem quarenta e cinco periódicos de psicologia, sendo vinte e nove publicados na região Sudeste, doze na região Sul, dois na região Centro-Oeste e dois na região Nordeste.

\section{Delineamento das Pesquisas}

No delineamento das pesquisas constantes nas publicações, observa-se uma variabilidade de abordagens metodológicas adotadas nos estudos. As nove produções selecionadas utilizaram como metodologia os seguintes tipos de pesquisa: estudo teórico, pesquisa e intervenção, estudo de casos, revisão da literatura, pesquisa transversal, pesquisa de campo e pesquisa observacional $(n=2)$. Acrescenta-se que todos os estudos empíricos incluídos na análise são de natureza qualitativa.

De acordo com Minayo (2010), a escolha do delineamento da pesquisa ocorre em razão do fenômeno pesquisado. Dessa maneira, dá-se preferência à abordagem qualitativa nos estudos sobre a relação família-escola. Tal opção ocorre porque, de maneira geral, essas pesquisas se dedicam aos procedimentos de interpretação, a partir dos dados coletados, situados em um determinado contexto. Assim, de alguma forma, expressam parte da realidade do indivíduo com base no que é verbalizado, características próprias das pesquisas qualitativas. 


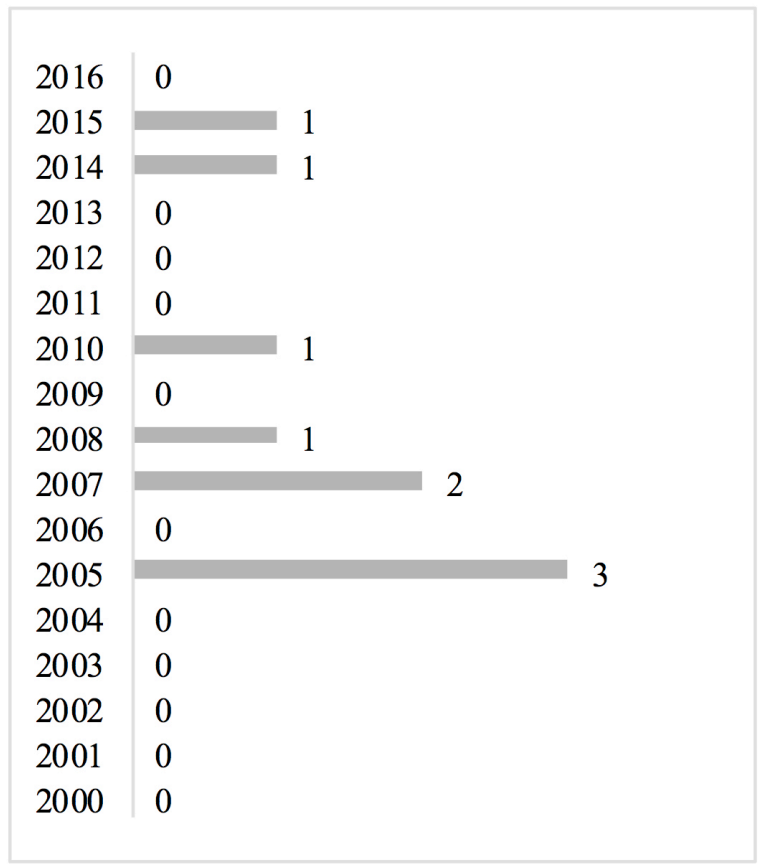

Gráfico 1. Frequência das publicações, no âmbito da psicologia escolar, sobre a relação família-escola no período de 2000 a 2016.

\section{Amostra e Instrumentos}

No que se refere à amostra, os estudos analisados tiveram como participantes: pais e professores $(n=$ 3); professores, coordenadores pedagógicos, diretores e pais $(n=1)$; psicólogos escolares, professores, pais e alunos $(n=1)$; equipe tecnicopedagógica e professores $(n=1)$; mães, pais e professores $(n=1)$.

Como se observa, as pesquisas apresentam amostras envolvendo dois ou mais atores escolares. Isso permite inferir que os pesquisadores têm adotado uma perspectiva mais ampla no estudo das relações família-escola, considerando os diversos sujeitos que as compõem. Resultado diferente foi encontrado por Guzzo (1990), quando analisou as produções nas décadas de 1970 e 1980 sobre a relação família-escola. Conforme seu estudo, o foco de intervenção se direcionava ao grupo de pais de estudantes, considerados como principais responsáveis por promover relações harmoniosas entre família e escola.

Embora as produções tenham privilegiado os diversos atores escolares, as pesquisas ainda apontam tensões e desencontros entre tais atores. Não obstante os estudos aqui investigados façam parte da área da psicologia escolar, em apenas uma das produções, o psicólogo escolar esteve entre os participantes das pesquisas. Esse dado requer uma reflexão sobre as produções nesse campo de análise acerca da relação família-escola, do ponto de vista psicológico, tendo em vista a baixa participação do psicólogo escolar nesse tipo de pesquisa. Tal constatação pode revelar uma falta de clareza a respeito das funções desse profissional nos meios escolares e educacionais. Considerando esse pressuposto, as produções científicas nacionais e internacionais deveriam explorar a questão de forma mais pontual. Os pesquisadores deveriam investigar de que forma a atuação do psicólogo escolar, no contexto da relação família-escola, pode ser desenvolvida, buscando potencializar o processo de ensino-aprendizagem.

Em relação aos instrumentos de pesquisa relatados, constatou-se variabilidade de recursos. Foram utilizados, de maneira mais significativa, instrumentos adotados em pesquisa qualitativa, a exemplo de entrevistas $(n=5)$, observações $(n=3)$, questionários $(n=$ 2), ficha de dados $(n=1)$, distribuição de folder $(n=1)$ e dinâmica $(n=1)$. É importante ressaltar que tais instrumentos não foram excludentes nas pesquisas, havendo estudos que fizeram uso de mais de um recurso. Esses instrumentos vêm sendo utilizados, de forma sistemática, por pesquisadores da área da psicologia escolar no desenvolvimento de seus estudos (Moreira \& Guzzo, 2014; Silva Neto, Guzzo, \& Moreira, 2014).

\section{Principais Resultados dos Estudos}

Os estudos analisados apresentaram os seguintes resultados: a constatação de que existe uma submissão das famílias ao saber da escola; uma postura moralizadora e normativa das instituições de ensino quando têm contato com as famílias; dificuldades na comunicação entre famílias e escola. Acrescenta-se a isso a atribuição de responsabilidade às famílias pelo fracasso ou sucesso do aluno na escola. Tais constatações indicam que a relação família-escola tem sido marcada por situações vinculadas a algum problema (Garcia, 2005; Silveira, 2007; Oliveira, 2007; Silva, 2008; Oliveira \& Marinho-Araújo, 2010; Soares, 2014; Lima \& Chapadeiro, 2015).

Em seu estudo, Silva (2008) considera a necessidade de utilizar os problemas existentes na relação família-escola como fontes de desafio para potencializar a aprendizagem dos estudantes. A partir de pesquisa realizada em uma escola municipal, comprovou que é possível aproximar escola e famílias, utilizando como recurso a conscientização sobre práticas que podem ser melhoradas nessa relação, a exemplo da promoção do diálogo entre os atores escolares. 
Oliveira (2007) verificou que família e escola conhecem suas responsabilidades específicas. Entretanto, não reconhecem as funções compartilhadas pelas duas instituições. Essa ausência de compreensão sobre o papel conjunto da escola e da família no desempenho escolar de estudantes interfere diretamente no modo como ambas estabelecem suas relações. Garcia (2005), Oliveira (2007) e Silva (2008) apontaram ações possíveis de serem desenvolvidas por psicólogos escolares na relação família-escola. Em suas pesquisas, apresentaram propostas destacando a ideia de que cada contexto de intervenção deve ser estudado. Todavia, acrescentaram que suas especificidades devem ser consideradas antes da implementação de ações.

Em sua pesquisa, Garcia (2005) desenvolveu um modelo de análise de reuniões escolares orientado por indicadores, envolvendo, os seguintes aspectos: interdependência-conteúdo, estrutura ou forma, e dinâmica das relações. Essa proposta tem como meta reconfigurar as reuniões escolares e fomentar relações de parceria entre escola e famílias. Oliveira (2007) identificou, como competências específicas no campo de atuação do psicólogo escolar na relação família-escola, ações voltadas para os seguintes objetivos: mediação dos sentidos subjetivos que permeiam a relação dos pais com o rendimento escolar dos alunos; escuta aos alunos e demais atores escolares; definição das funções compartilhadas pelos dois sistemas; desenvolvimento da compreensão de que os alunos são mediadores da relação família-escola.

Ainda sobre as ações que podem ser executadas por psicólogos escolares na relação família-escola, Silva (2008) destacou os seguintes aspectos: relevância do desenvolvimento de uma postura de diálogo da escola com as famílias; fortalecimento da relação entre professores e alunos; incentivo aos professores no sentido de promoverem maiores contatos com as famílias.

Também Reali \& Tancredi (2005) relataram, em seu estudo, os resultados de uma intervenção que visava a fortalecer as relações escola-família. A experiência se desenvolveu por meio de um programa de formação continuada para professores, no seu local de trabalho. O programa propiciou a realização de encontros com os professores de uma instituição pública de ensino para definir uma agenda de trabalhos voltada ao objetivo de promover aproximações entre família e escola.

A intervenção permitiu a realização de ações, tais como: busca de informações junto aos pais sobre temas que gostariam que fossem discutidos na escola; planejamento de atividades a serem desenvolvidas junto aos pais sobre temas de seu interesse; realização de reuniões com os familiares, envolvendo dinâmicas conduzidas pelos professores (previamente planejadas com a equipe de pesquisadores) e distribuição de folders explicativos sobre o projeto pedagógico da escola.

Ao final da programação, os professores participantes fizeram uma reflexão sobre os seguintes pontos: as famílias de seus alunos; a relação escola-famílias; os conteúdos escolares e sua importância; a forma pela qual os alunos se desenvolvem e para que são ensinados. Abriu-se ainda espaço para a ressignificação de concepções sobre as famílias dos estudantes e a troca de experiências entre família e escola, favorecendo o estreitamento da relação entre ambas.

É relevante ressaltar que as pesquisas de Polonia e Dessen (2005), Silveira (2007) e Oliveira e Marinho-Araújo (2010) já apontavam a necessidade de uma maior ampliação de estudos sobre a relação família-escola, no âmbito da psicologia escolar. Para as autoras, é imprescindível que se estimulem as produções acadêmicas direcionadas ao estudo do envolvimento da família com a escola. Tais produções devem ser transformadas em mecanismos que contribuam para o desenvolvimento de políticas e de programas educacionais. Destacaram ainda a urgência da construção de uma interação família-escola que promova a integração dos contextos de socialização das crianças, de modo a permitir, de maneira clara, a definição de papéis e funções educativas.

A verificação das autoras sobre o número reduzido de produções acerca da temática foi feita entre os anos de 2005 e 2010. Porém, na atualidade, verificam-se ainda as lacunas apontadas. A partir da perspectiva da psicologia crítica e reflexiva, considera-se que a relação família-escola é um campo amplo para intervenções psicossociais, revelando-se como uma área de atuação do psicólogo escolar. Esse profissional deve desenvolver uma atuação voltada aos aspectos que podem modificar essa relação, favorecendo a promoção do desenvolvimento dos agentes envolvidos (Moreira \& Guzzo, 2014).

\section{Considerações Finais}

O objetivo desta pesquisa foi identificar estudos, no âmbito da psicologia escolar, sobre intervenções na relação família-escola, com base no levantamento da literatura. Observou-se a necessidade de desenvolver estudos que explicitem, de forma mais detalhada, as estratégias que compõem as modalidades de atuação 
de psicólogos escolares junto a esses dois grupos. Conforme se observou, a maior parte das produções nessa área tem analisado a relação família-escola do ponto de vista psicológico, não sendo essa questão direcionada ao psicólogo escolar. Essa lacuna pode revelar falta de clareza acerca das funções desse profissional nos meios educacionais.

Destacou-se a relevância de explorar o trabalho do psicólogo como mediador da relação família-escola, com vista a favorecer o desenvolvimento de ações que fortaleçam essa relação. Tais ações irão provocar a conscientização dos agentes escolares e propiciar um melhor entendimento das famílias sobre o seu papel no processo de escolarização dos filhos.

Estagiários e profissionais do campo da psicologia escolar devem tomar conhecimento da gama de ações que podem ser efetivadas nas escolas e outros espaços educacionais para reconfigurar as relações entre família e escola. Enfatiza-se, como elemento essencial para uma atuação efetiva diante dessa questão, uma formação básica que possibilite a apreensão de pressupostos teórico-metodológicos. Dessa forma, é possível demarcar as especificidades do trabalho do psicólogo escolar, fortalecendo, de forma dialética, a relação entre teoria e prática profissional.

Em suas propostas de intervenção em psicologia escolar (Neves \& Almeida, 2003; Sant'Ana \& Guzzo, 2014; Silva Neto, Guzzo, \& Moreira, 2014), estes estudiosos têm destacado as ações dos psicólogos junto às famílias, na perspectiva de reverter cenários nos quais o desgaste da relação família-escola se expressa na fala de atores escolares, especialmente de professores (Aquino et al., 2015). Reafirma-se, neste estudo, a necessidade de desenvolver ações mais específicas que interfiram na relação família-escola, partindo de uma concepção integrada, crítica e colaborativa de toda a comunidade escolar.

Em face das conclusões apontadas, sugere-se a realização de pesquisas, em nível de graduação e pós-graduação, envolvendo familiares, equipe escolar e estudantes. O principal objetivo dessas pesquisas deverá ser procurar entender as fragilidades e tensões que permeiam o envolvimento da família com a escola. Pode-se também reforçar o compromisso que os profissionais da educação devem assumir com o desenvolvimento de crianças e adolescentes.

Por fim, defende-se a necessidade de promover as investigações acerca da relação família-escola, como, por exemplo, a divulgação de projetos de intervenção por meio de publicações, desde a graduação.
É pertinente enfatizar que as pesquisas podem revelar as complexidades, peculiaridades e possibilidades de intervenção de psicólogos escolares na relação família-escola. Dessa forma, é possível fortalecer o trabalho desse profissional em contextos escolares.

\section{Referências}

Bhering, E., \& Siraj-Blatchford, I. (1999). A relação escola-pais: Um modelo de trocas e colaboração. Cadernos de Pesquisa, 106, 191-216. doi: 10.1590/ S0100-15741999000100010

Braz-Aquino, F. S., \& Albuquerque, J. A. (2016). Contribuições da teoria histórico-cultural para a prática de estágio supervisionado em psicologia escolar. Estudos de Psicologia (Campinas), 33(7), 225-235. doi: 10.1590/1982-02752016000200005

Aquino, F. S., Lins, R. P. S., Cavalcante, L. A., \& Gomes, A. R. (2015). Concepções e práticas de psicólogos escolares junto a docentes de escolas públicas. Revista Quadrimestral da Associação Brasileira de Psicologia Escolar e Educacional, 19(1), 71-78. doi: 10.1590/2175-3539/2015/0191799

Cavalcante, L. A. (2015). O psicólogo na rede pública de educação: Concepções, formação e atuação profissional. (Dissertação de mestrado). Universidade Federal da Paraíba, Paraíba, Brasil.

Cavalcante, L. A., \& Aquino, F. S. B. (2013). Ações de psicólogos escolares de João Pessoa sobre queixas escolares. Psicologia em Estudo (Impresso), 18(2), 353362. doi: 10.1590/S1413-73722013000200016.

Carvalho, M. E. P. (2000). Relações entre família e escola e suas implicações de gênero. Cadernos de Pesquisa, 110, 143-155. doi: 10.1590/ S0100-15742000000200006.

Garcia, H. H. G. O. (2005). Família e escola na educação infantil: Um estudo sobre reunião de pais (Dissertação de mestrado). Instituto de Psicologia da Universidade de São Paulo.

Moreira, A. P. G., \& Guzzo, R. S. L. (2014). A psicologia que defendemos na escola que vivemos: uma contribuição dos bastidores do "Voo da Águia". Em Guzzo, R. S. L. (Ed.). Psicologia Escolar: Desafios e bastidores da educação pública. Campinas: Alínea.

Guzzo, R. S. L. (1990). A família e a educação: Uma perspectiva da integração família-escola. Estudos de 
Psicologia (Campinas), 7(1), 134-139. Recuperado de http://www.scielo.br/scielo.php?script=sci_nli nks\&ref $=000117 \&$ pid $=$ S0103166X201000010001 $200008 \& \ln g=$ en

Lima, T. B. H., \& Chapadeiro, C. A. (2015). Encontros e (des)encontros no sistema família-escola. Psicologia Escolar e Educacional, 19(3), 493-502. doi: 10.1590/2175-3539/2015/0193879

Marcondes, K. H. B., \& Sigolo, S. R. R. L. (2012). Comunicação e envolvimento: Possibilidades de interconexões entre família-escola? Paidéia, 22(51), 91-99. doi: 10.1590/S0103-863X2012000100011

Marques, R. (2002). O envolvimento das famílias no processo educativo: Resultados de um estudo em cinco países. Recuperado de http://saladepraticas.blogspot.com. br/2015/11/o-envolvimento-das-familias-no-processo.html?view $=$ flipcard

Minayo, M. C. de C. (2010). O desafio do conhecimento: Pesquisa qualitativa em saúde. (12 ed.) São Paulo: Hucitec-Abrasco.

Neves, M. M. B. da J., \& Almeida, S.F.C. (2003). A atuação da psicologia escolar no atendimento aos alunos encaminhados com queixas escolares. Em S. F. C. de Almeida (Ed.). Psicologia Escolar: Ética e competências na formação e atuação profissional. Campinas: Alínea.

Nunes, L. de L., Alves, S. S., Ramalho, J. V., \& Aquino, F. S. B. (2014). Contribuições da perspectiva crítica de base histórico-cultural para a produção científica em psicologia educacional. Educação e Pesquisa, 40(3), 667-682. doi: 10.1590/ s1517-97022014091471

Oliveira, L. C. F. (2002). Escola e família numa rede de (des) encontros: Um estudo das representações de pais e professores. São Paulo: Cabral Editora.

Oliveira, C. B. E (2007). Psicologia escolar e a relação familia-escola no Ensino Médio: Estudando as concepções desta relação (Tese de doutorado). Recuperado de http:// bdtd.bce.unb.br/tedesimplificado/tde_busca/arquivo.php?codArquivo $=2673$

Oliveira, C. B. E., \& Marinho-Araújo, C. M. (2010). A relação família-escola: Intersecções e desafios. Estudos de Psicologia, 27(1), 99-108. doi: 10.1590/ S0103-166X2010000100012
Oliveira, K. L., Cantalice, L. M., Joly, M. C. R. A., \& Santos, A. A. A. (2006). Produção científica de 10 anos da revista Psicologia Escolar e Educacional (1996/2005). Psicologia Escolar Educacional. 10(2), 283-292. doi: 10.1590/S1413-85572006000200011

Polonia, A. da C., \& Dessen, M. A. (2005). Em busca de uma compreensão das relações entre família e escola. Psicologia Escolar e Educacional, 9(2), 303-312. doi: 10.1590/S1413-85572005000200012

Reali, A. M. M. R., \& Tancredi, R. M. S. P. (2005). A importância do que se aprende na escola: a parceria escola-famílias em perspectiva. Paidéia, 15(31), 239247. doi: 10.1590/S0103-863X2005000200011

Sant'Ana, I. M., \& Guzzo, R. S. L. (2014). O psicólogo escolar e o projeto político-pedagógico da escola: diálogos e possibilidades de atuação. Em R. S. L. Guzzo (Ed.), Psicologia Escolar: desafios e bastidores na educação pública (pp.85-109).

Silva, M. L. S. (2008). Relação escola-família: Possibilidade de aproximação em situação de dificuldades de aprendizagem dos alunos (Dissertação de mestrado). Pontifícia Universidade Católica de São Paulo- PUC-SP.

Silva, S. S. G. T., Aquino, F. S. B., Albuquerque, J. A., \& Rodrigues, L. F. (2015) "Estágio supervisionado em psicologia escolar: Relato de práticas". Em Anais do $9^{\circ}$ Congresso Norte e Nordeste de Psicologia (p. 662-663).

Silva Neto, W. M. F. S., Guzzo, R. S. L., \& Moreira, A. P. G. (2014). Estagiários de psicologia na escola: O que os bastidores revelam para a formação profissional? Em Guzzo, R. S. L. (Ed.), Psicologia Escolar: Desafios e bastidores na educação pública. Campinas: Alínea.

Silveira, L. M. O. B. (2007). A interação família-escola frente aos problemas de comportamento da criança: Uma parceria possivel? (Tese de doutorado). Pontifícia Universidade Católica do Rio Grande do Sul, Porto Alegre.

Soares, C. C. (2014). Relação família-escola no contexto da inclusão de crianças com transtorno do espectro autista (Dissertação de mestrado). Universidade do Vale do Rio dos Sinos- UNISINOS.

Recebido em: 05-09-2016

Reformulado em: 20-11-2016

Aprovado em: 16-12-2016 
Sobre as autoras:

Jéssica Andrade de Albuquerque é psicóloga, mestra em Psicologia Social e doutoranda no Programa de Pós-graduação em Psicologia Social da Universidade Federal da Paraíba (PPgPS/UFPB), e membro do Núcleo de Estudos em Interação Social e Desenvolvimento Infantil.

E-mail: jessica.a.psi@gmail.com

Fabíola de Sousa Braz-Aquino é professora adjunta no curso de Psicologia da Universidade Federal da Paraíba e do Programa de Pós-Graduação em Psicologia Social (UFPB), pesquisadora do Núcleo de Estudos em Interação Social e Desenvolvimento Infantil, membro do GT de Psicologia Escolar Educacional da ANPEPP e supervisora de Estágio Supervisionado Curricular em Psicologia Escolar Educacional, em contextos públicos de educação.

E-mail: fabiolabrazaquino@cchla.ufpb.br

Contato com as autoras:

Rua Mário Batista Junior, 75, Ed. Quinta Avenida, Apto. 301, Bairro Miramar

João Pessoa-PB, Brasil

CEP: 58043130 